\title{
Advantages in the design of open-pit and quarries by computer mean

\author{
Lluís Sanmiquel $^{1}$, Marc Bascompta ${ }^{1}$, Nor Sidki ${ }^{2}$, Hernán Anticoi ${ }^{2}$ \\ ${ }^{1}$ ICL Chair in Sustainable Mining. \\ Polytechnic University of Catalonia (UPC), Avenue Bases de Manresa, 61-73, 08242-Manresa Spain \\ lluis.sanmiquel@upc.edu; marc.bascompta@upc.edu \\ ${ }^{3}$ Department of Mining Engineering, Industrial and ICT \\ Polytechnic University of Catalonia (UPC), Avenue Bases de Manresa, 61-73, 08242-Manresa Spain \\ nor.sidki@upc.edu; hernan@emrn.upc.edu
}

\section{Extended Abstract}

In the last 15 years, there has been a great advance and diffusion of specific commercial software focused on mining design, planning and optimization, such as Vulcan, RecMin or Datamine. Thus, the case of this study will focus on the design of the expansion of an aggregate quarry carried out using Vulcan. An analysis of the most important advantages and disadvantages during the design of a quarry is through the use of this specific software, following the process below:

1- Block model creation based on an initial drilling mesh with the aim to model the expansion of the extractive activity. This model had information about density, grade of the resource and bloc size.

2- Economic analysis taking into account the main characteristics of the quarry.

3- The study of different scenarios based on several parameters such as: economic, geotechnical and specific constraints of the mine. Each scenario was optimized by the Lerchs-Grossmann method in order to find the most economical design according to the parameters considered in each case. Ensuring the highest economic profitability while complying the mining design requirements established in each case. (Baek et al., 2016)

The results obtained showed that the use of this type of tools provide considerable advantages in the design of a quarry and its economic optimization. Besides, it can also help to increase safety levels and solve environmental issues related to the mining activity.

\section{References}

[1] Baek, J., Choi, Y., Park, H. (2016). Uncertainty Representation Method for Open Pit Optimization Results Due to Variation in Mineral Prices, Minerals, 6(1), 17. https://doi.org/10.3390/min6010017.

[2] H.J. Oh and S. Lee, "Integration of ground subsidence hazard maps of abandoned coal mines in Samcheok, Korea," International Journal of Coal Geology, 2011, 86(1), pp. 58-72.

[3] J. Yin, D. Yu, and R. Wilby, "Modelling the impact of land subsidence on urban pluvial flooding: A case study of downtown Shanghai, China," Science of the Total Environment, 2016, 544, pp. 744-753. 